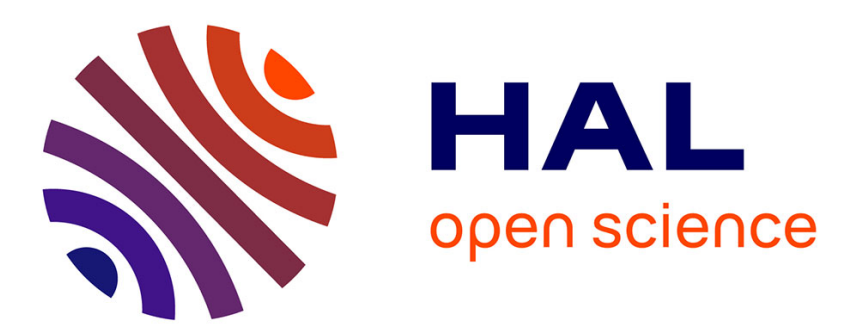

\title{
Shock enhancement of cellular structures under impact loading: Part II Analysis
}

Stéphane Pattofatto, Ibrahim Elnasri, Han Zhao, Elli Tsitsiris, François Hild, Yannick Girard

\section{- To cite this version:}

Stéphane Pattofatto, Ibrahim Elnasri, Han Zhao, Elli Tsitsiris, François Hild, et al.. Shock enhancement of cellular structures under impact loading: Part II Analysis. Journal of the Mechanics and Physics of Solids, 2007, 55 (12), pp.2672-2686. 10.1016/j.jmps.2007.04.004 hal-00199386

\section{HAL Id: hal-00199386 https://hal.science/hal-00199386}

Submitted on 19 Dec 2007

HAL is a multi-disciplinary open access archive for the deposit and dissemination of scientific research documents, whether they are published or not. The documents may come from teaching and research institutions in France or abroad, or from public or private research centers.
L'archive ouverte pluridisciplinaire HAL, est destinée au dépôt et à la diffusion de documents scientifiques de niveau recherche, publiés ou non, émanant des établissements d'enseignement et de recherche français ou étrangers, des laboratoires publics ou privés. 


\title{
Shock enhancement of cellular structures under impact loading: Part II Analysis
}

\author{
S. Pattofatto, ${ }^{1}$ I. Elnasri, ${ }^{1}$ H. Zhao, ${ }^{1 *}$ H. Tsitsiris ${ }^{1}$ F. Hild ${ }^{1}$ and Y. Girard ${ }^{2}$ \\ ${ }^{1}$ Laboratoire de Mécanique et Technologie (LMT-Cachan) \\ ENS-Cachan/CNRS-UMR8535/Université Paris 6 \\ 61 avenue du Président Wilson, F-94235 Cachan Cedex, France \\ ${ }^{2}$ EADS-CCR Suresnes, 12 bis rue Pasteur \\ F-92152 Suresnes Cedex, France
}

\begin{abstract}
Numerical simulations of two distinct testing configurations using a Hopkinson bar (pressure bar behind/ahead of the shock front) are performed with an explicit finite element code. It allows us to confirm the observed test data such as velocity and force time histories at the measurement surface. A comparison of the simulated local strain fields during shock front propagation with those measured by image correlation provides an additional proof of the validity of such simulations.

Very simple rate insensitive phenomenological constitutive model are used in such simulations. It shows that the shock effect is captured numerically with a basic densification feature. It means that strength enhancement due to shock should not be integrated in the constitutive model of foam-like materials used in industrial FE codes.

In order to separate shock enhancement from entire strength enhancement, an improvement of an existing model with easily identifiable parameters for shock enhancement prediction is proposed. For a quick estimate of the shock enhancement level, a simple power law densification model is proposed instead of the classical RPPL model proposed by Reid and co-workers (Tan et al. 2005). It is aimed at eliminating the parameter identification uncertainty of the RPPL model. Such an improved model is easily identifiable and gives a good prediction of the shock enhancement level.
\end{abstract}

*Corresponding author: zhao@,1mt.ens-cachan.fr 


\section{Introduction}

The concept of shock enhancement effect under high speed impact $(>100 \mathrm{~m} / \mathrm{s})$ was originally proposed by Reid and Peng (1997) to explain testing results on woods. Afterwards, a number of authors also reported this effect for various cellular materials at high impact speeds (Lopatnikov et al., 2003; 2004; Tan et al. 2002, 2005; Rodford et al., 2005).

For relatively low impact speeds around the so-called critical velocity under which shock enhancement is not significant $(\sim 50 \mathrm{~m} / \mathrm{s})$, shock enhancement is experimentally studied with a 60-mm diameter Nylon Hopkinson bar (see companion paper, Elnasri et al., 2007). With a single bar, tests with two configurations using a large diameter soft Hopkinson bar behind/ahead of the shock front allow for the estimation of the stress jump across the shock front as well as the shock front speed. Such tests show a significant shock enhancement for two materials (namely, Alporas foam and hollow spheres).

Experimental data in previous works prove then the existence of such shock effect (Tan et al. 2002, 2005; Nasri et al. 2007). However, only global measurements are available (velocity / force in the pressure bar, or surface strain maps). For a better understanding of the shock enhancement mechanism, a numerical study is a complementary means. It provides all the virtual details that are difficult to measure in a real test. It will also help us confirm which model characteristics of foam-like materials are responsible for this shock enhancement. Besides, it is also important to determine how to deal with such enhancement in industrial applications. For example, is it necessary or not to introduce the shock enhancement effect in the material constitutive law, especially for impact speeds around the so-called critical velocity where the shock effect is of the same magnitude as materials rate sensitivity.

For this purpose, numerical analyses for the two testing configurations using LS-Dyna explicit finite element code with a macroscopic constitutive law (crushable foam) are performed. They show that such a simple rate insensitive constitutive model is able to reproduce the essential features of shock enhancement. It may be concluded that (i) the numerical shock enhancement depends only on a simple macroscopic densification constitutive law, and (ii) the nature of the microstructure of cellular materials has no significant influence.

Therefore, shock enhancement should be eliminated from the entire observed enhancement for the constitutive law development. A simple prediction is also needed. For example, the Rigid Perfectly Plastic Locking (RPPL) model proposed by Reid and Peng 
(1997) gives a fast estimation. However, the shock stress jump and shock front speed predicted by the RPRL model are too sensitive to the parameters (e.g., the rigid locking strain). In addition, these parameters are difficult to choose. It leads us to propose another model that assumes a power law densification. Such a model enables for the elimination of the uncertainty induced by the arbitrary choice of the rigid locking strain in the RPPL model and it gives a close-form expression and a good prediction.

\section{Numerical analysis}

Numerical analyses are performed to have access to local values that cannot be measured in real tests. It is also aimed at verifying if the shock enhancement depends only on the macroscopic phenomenological feature or may depend also on the microstructure of cellular materials. If a simple phenomenological foam-like material behaviour is sufficient to reproduce all the shock enhancement features, it means that the microstructure will have a very limited influence on shock enhancement.

\subsection{FE model}

The LS-Dyna explicit finite element code is used to perform the simulations. The specimen whose diameter is $60 \mathrm{~mm}$ and thickness $40 \mathrm{~mm}$ (Figure 1) is meshed with 32,000 cubic 8-node elements (with 20 elements in the length).

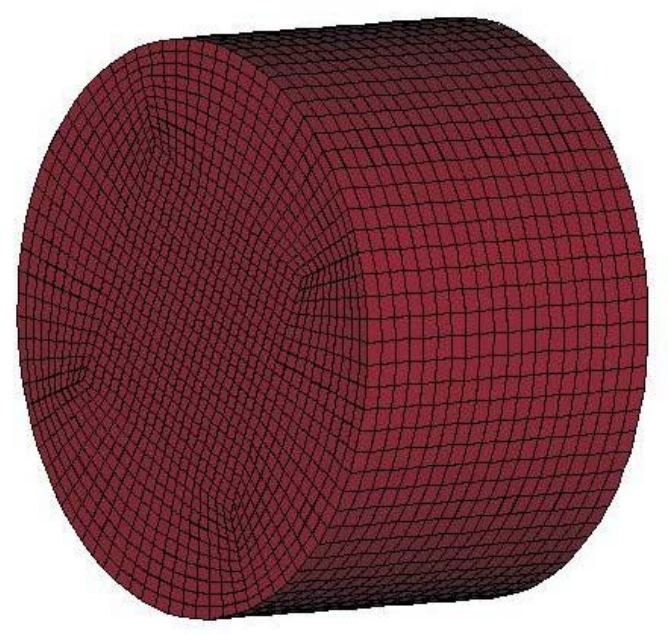

Figure 1. Finite element mesh of the specimen 
The constitutive law of the foam is given by the so-called "crushable foam model" available in the LS-Dyna code (Hallquist, 1998). At time step $n$, the crushable foam model defines at first a trial stress tensor $\left(\sigma_{\mathrm{ij}}^{\mathrm{n}+1}\right)^{\text {trial }}$ at time step $n+1$, based on an elastic prediction

$$
\left(\sigma_{\mathrm{ij}}^{\mathrm{n}+1}\right)^{\text {trial }}=\sigma_{\mathrm{ij}}^{\mathrm{n}}+\mathrm{E} \dot{\varepsilon}_{\mathrm{ij}}^{\mathrm{n}} \Delta \mathrm{t}^{\mathrm{n}}
$$

where $\sigma_{\mathrm{ij}}^{\mathrm{n}}, \dot{\varepsilon}_{\mathrm{ij}}^{\mathrm{n}}, \Delta \mathrm{t}^{\mathrm{n}}$ are respectively the stress tensor, the strain rate and time step; $\mathrm{E}$ is the elastic constant.

Afterwards, the principal stresses of this trial stress tensor $\sigma_{\mathrm{k}}^{\text {trial }}, \mathrm{k}=1,3$ are compared to the yield stress $\sigma_{y}$. If $\left|\sigma_{i}^{\text {trial }}\right|>\sigma_{y}$, the principal stress is scaled back by $\sigma_{i}^{n+1}=\sigma_{y} \sigma_{i}^{\text {trial }} /\left|\sigma_{i}^{\text {trial }}\right|$. The new stress tensor $\sigma_{\mathrm{ij}}^{\mathrm{n}+1}$ is finally obtained by transforming scaled principal stresses to the initial coordinate system. The yield stress $\sigma_{y}$ is considered as a function of volumetric strain $\varepsilon_{v}$

$$
\varepsilon_{\mathrm{v}}=1-\frac{\mathrm{V}}{\mathrm{V}_{0}}
$$

where $V$ is the volume and $V_{0}$ the initial volume of an element.

From experimental nominal stress-strain curves, it is straight forward to derive the volumetric strain $\varepsilon_{\mathrm{v}}$ from nominal strain $\varepsilon_{\text {nominal, }}$ given that the Poisson's ratio is set to zero (Zhao et al., 2005)

$$
\varepsilon_{\mathrm{v}}=1-\frac{\mathrm{L}}{\mathrm{L}_{0}}=\varepsilon_{\text {nominal }}
$$

Figure 2 shows the flow stress-volumetric strain relationship used in the following simulations (defined by discrete points), which is derived from a compression test on Alporas foam (Elnasri et al., 2007). 


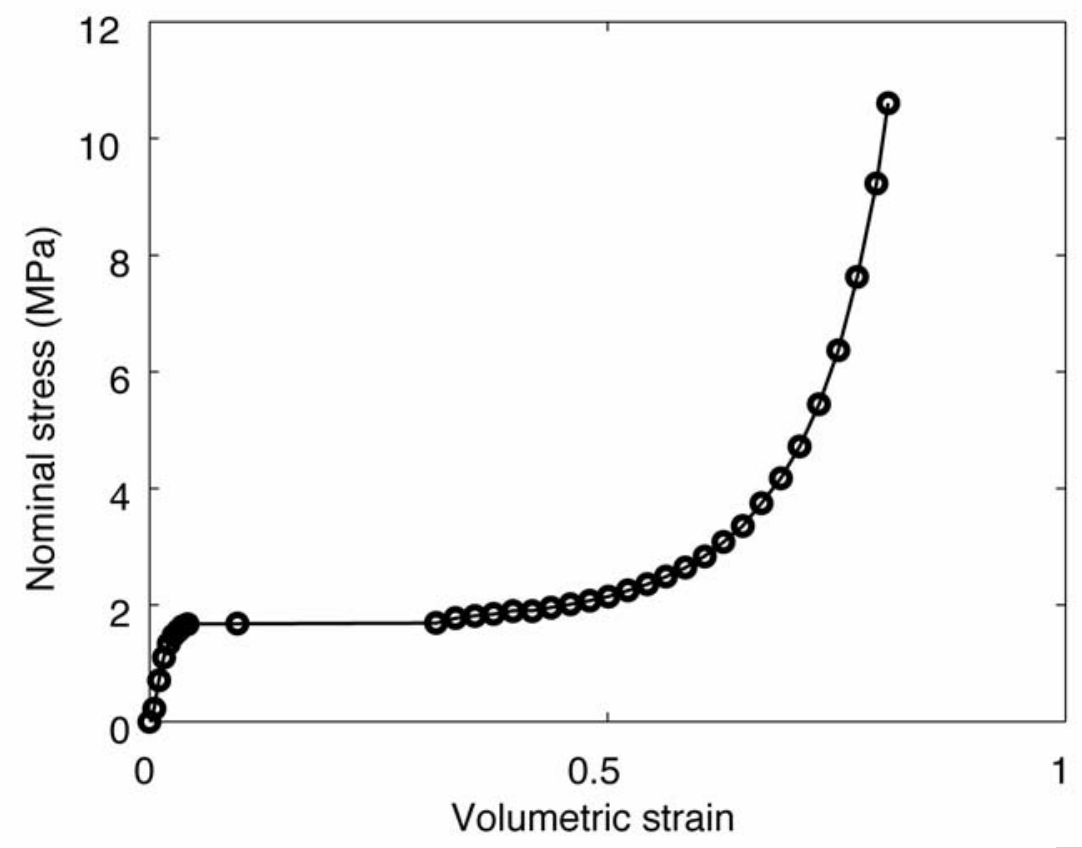

Figure 2. Input flow stress-volumetric strain relation for Alporas foam

\subsection{Numerical simulation for the two test configurations}

The two test configurations presented in a companion paper (Elnasri et al., 2007) are now analyzed.

\subsubsection{Configuration 1}

For test configuration 1 where the projectile strikes the foam specimen cemented on a 60-mm nylon Hopkinson pressure bar, the measured velocities are prescribed at both sides of the specimen by means of two moving rigid walls (Figure 3).

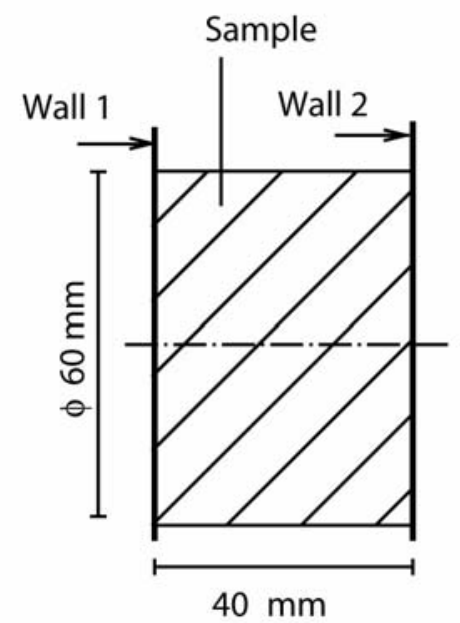

Figure 3. Boundary conditions for simulating test configuration 1 
The velocities of the rigid walls are shown in Figure 4.

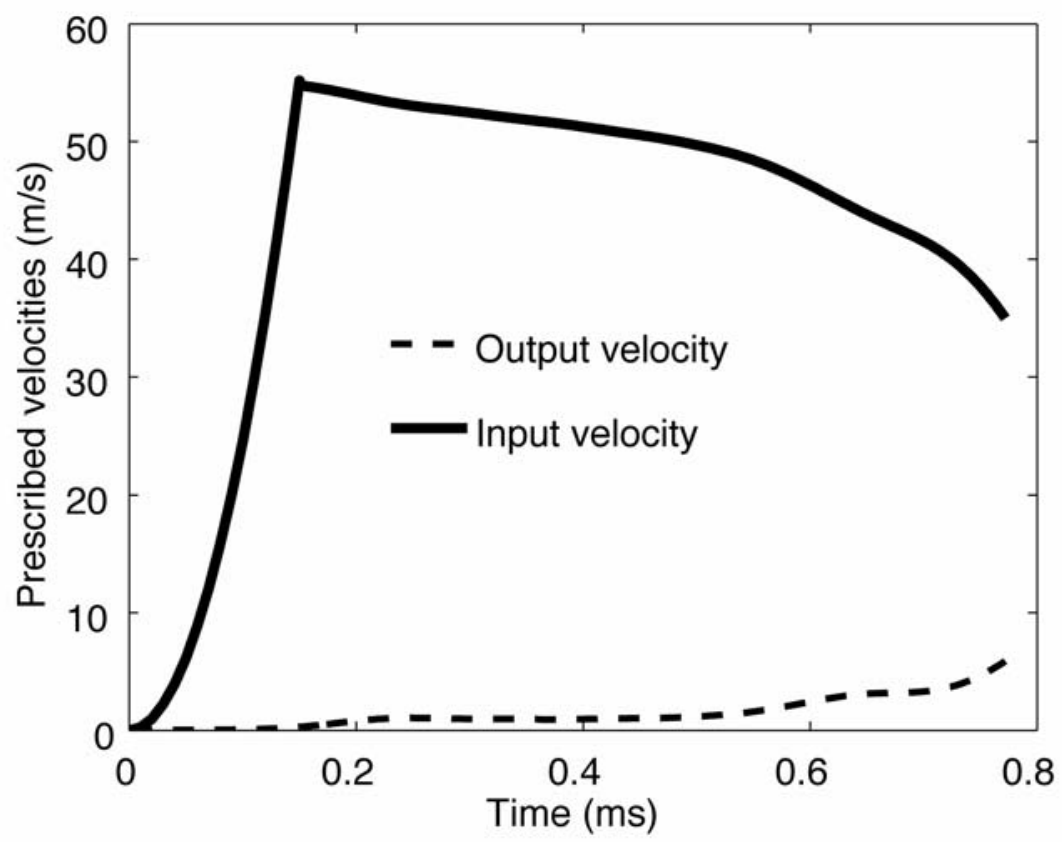

Figure 4. Input and output prescribed velocities for the moving rigid walls (config. 1)

The comparison between experimental and numerical results is carried out by computing the force ahead of the shock front measured by the Hopkinson bar. The good agreement between simulated and measured force / time histories (Figure 5) validates the FE model and the constitutive law. 


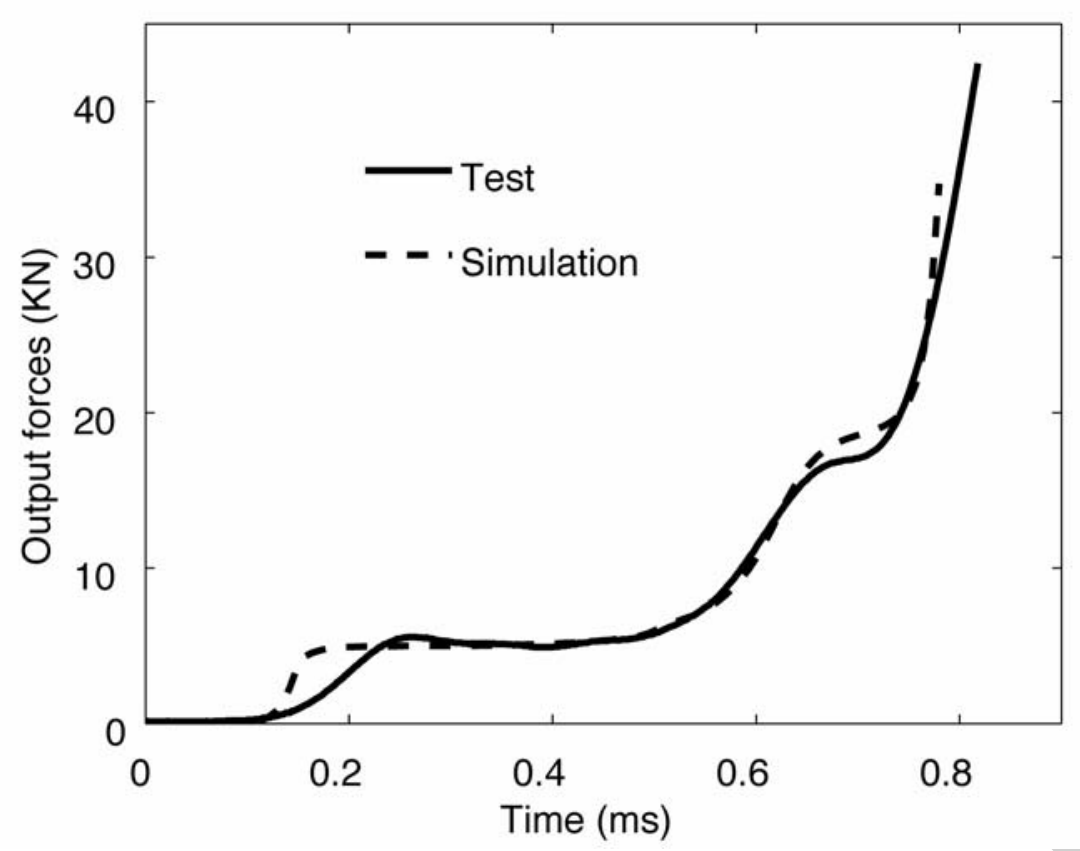

Figure 5. Comparison between simulated and measured force / time histories (config. 1)

\subsubsection{Configuration 2}

For test configuration 2 where the foam specimen is cemented on the projectile and strikes the Hopkinson pressure bar, the pressure bar is represented by a moving wall travelling at the measured velocity, in the same way as for configuration 1 . However, only the measured initial velocity is prescribed to the foam specimen and to the projectile considered as a rigid body (Figure 6). Here the mass of the real projectile used in the test is associated with the numerical rigid body projectile model.

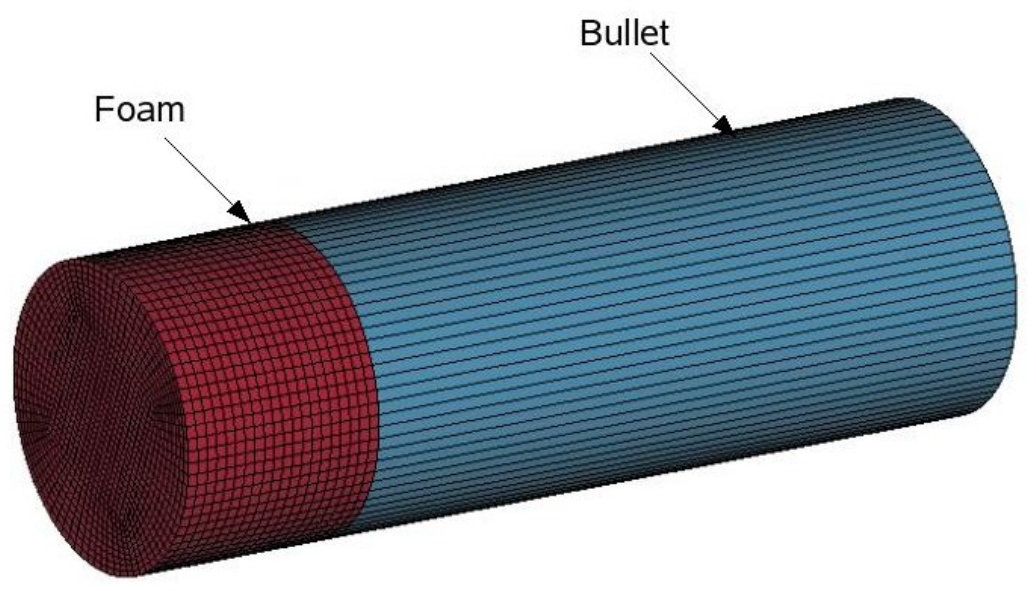

Figure 6. Foam and projectile against a moving rigid wall (config. 2) 
The comparison is also performed by considering the force measured by the Hopkinson bar (i.e., behind the shock front). Figure 7 shows a good agreement between simulated and measured forces.

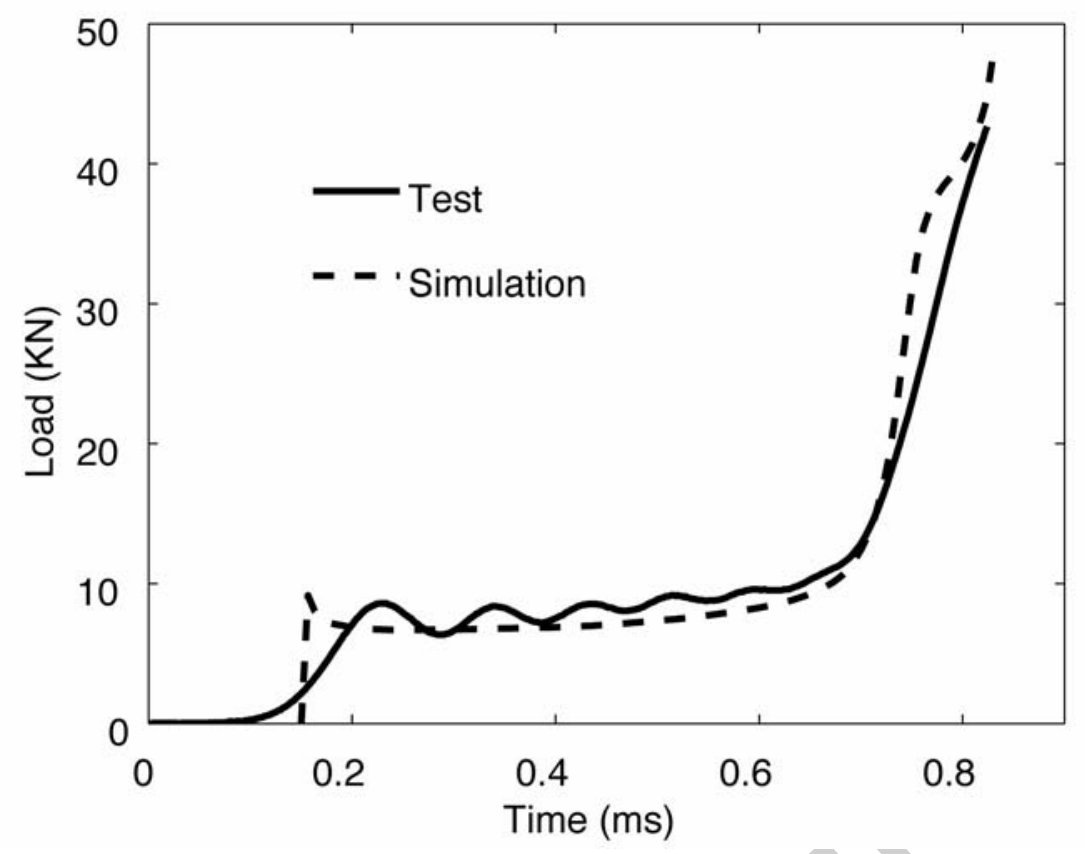

Figure 7. Comparison between simulated and measured force/ time histories (config. 2)

\subsection{Discussions on shock enhancement simulation}

The simulations of the two loading configurations provide a satisfactory agreement between the simulated and measured forces by Hopkinson bars. Since these two testing configurations are used to measure the force jump across the shock front, it is interesting to study the two forces across the shock front for a simulated test. If one takes the simulation of a test in configuration 1 as an illustration example, the simulated forces ahead of and behind the shock front are plotted in Figure 8. In Figure 8a, one notes that the history is similar to the measured forces between two testing configurations at $55 \mathrm{~m} / \mathrm{s}$ (Elnasri et al., 2007). In Figure $8 \mathrm{~b}$, a simulated test at $19 \mathrm{~m} / \mathrm{s}$ with the same constitutive model is shown, where no shock effect is observed. 


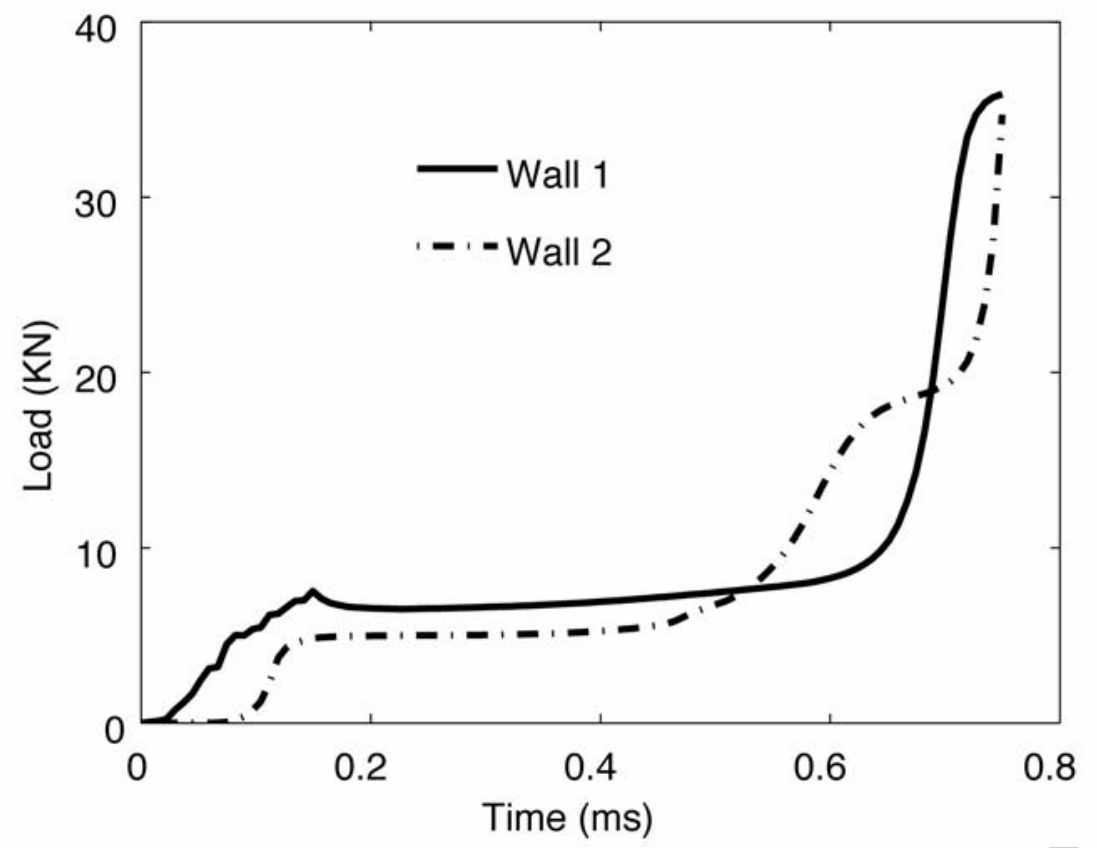

(a) Impact velocity: $55 \mathrm{~m} / \mathrm{s}$,

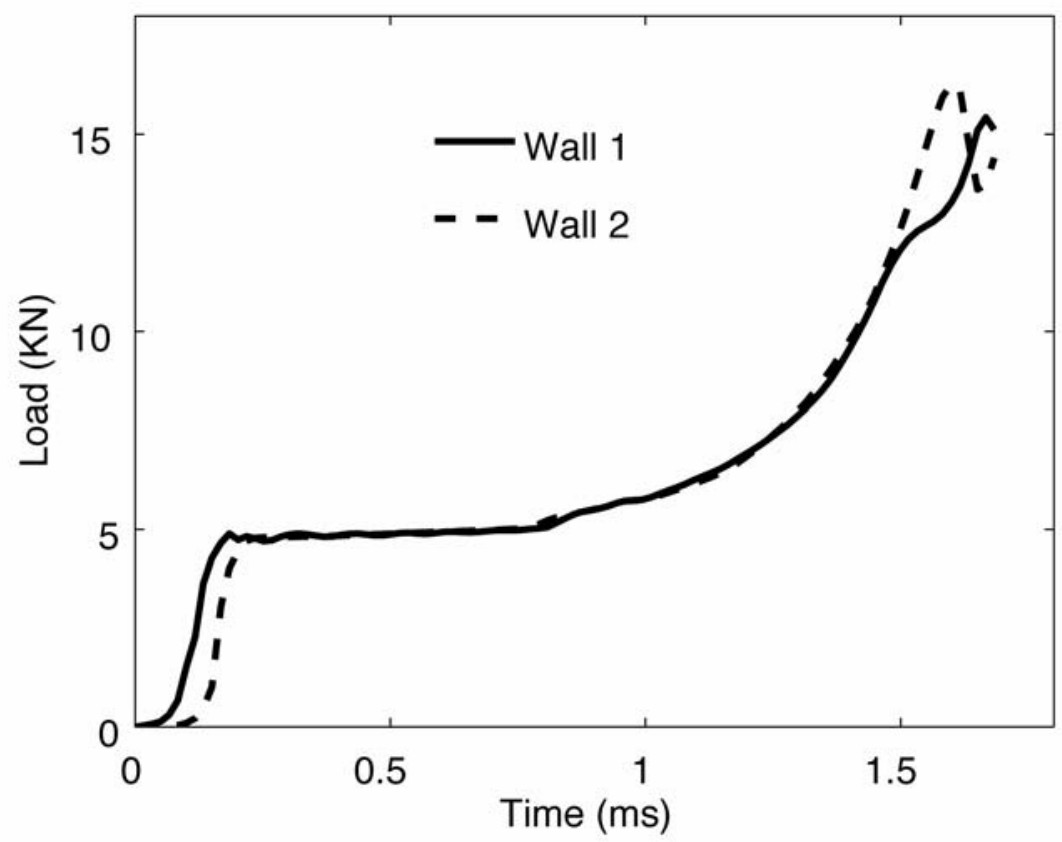

(b) Impact velocity: $19 \mathrm{~m} / \mathrm{s}$

Figure 8. Simulated forces ahead of and behind the shock front (config. 1)

A quantitative comparison between the simulated forces across the shock front in configuration 1 (see Figure 8a) and the two measured forces, supposed to be those across the 
shock front, obtained by two tests under different configurations is given in Figure 9. One concludes that the measured and simulated forces are close. This proves that the concept of testing with two configurations does provide a means of measuring simultaneously the forces at both sides and can be used to investigate shock enhancement.

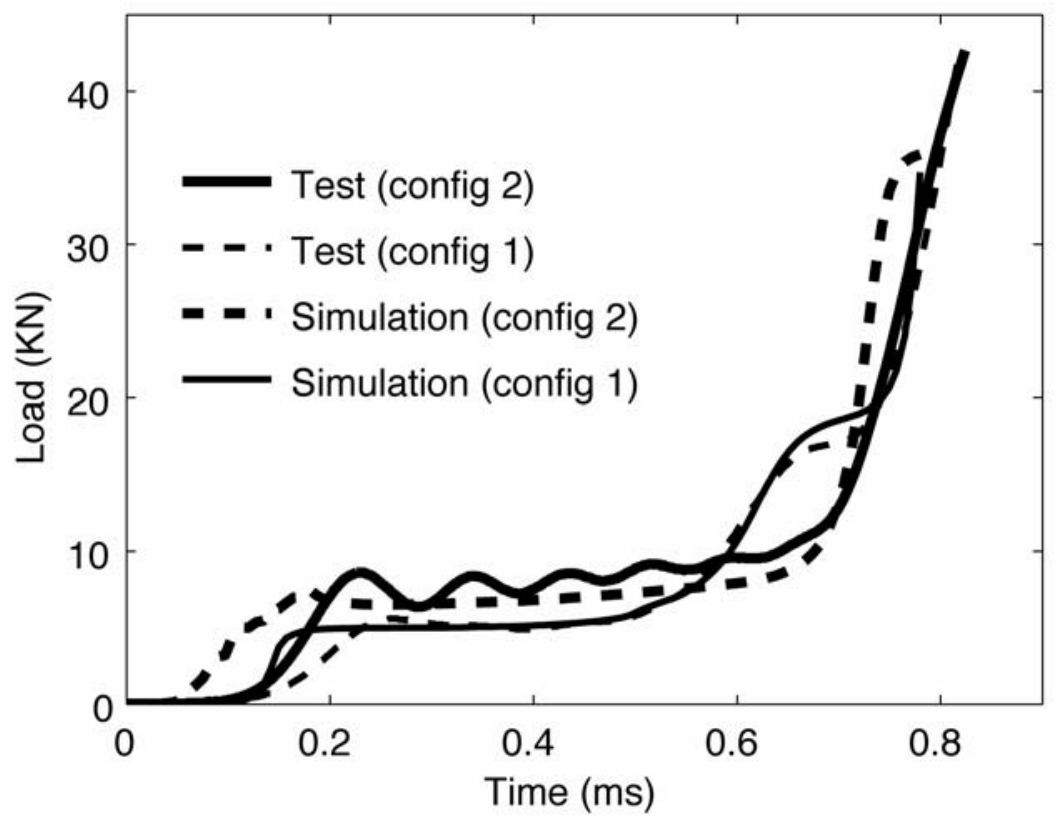

Figure 9. Comparison between experimental and simulated force histories

Let us now study the details of the strain discontinuity propagation. The simulated strain map at different instants is also compared with the strain field obtained by image correlation (see companion paper). The simulated average strain evaluated in the same manner as by image correlation post-processing (dotted line, Figure 10) is compared to the experimental data (solid line, Figure 10). A good agreement is obtained. 


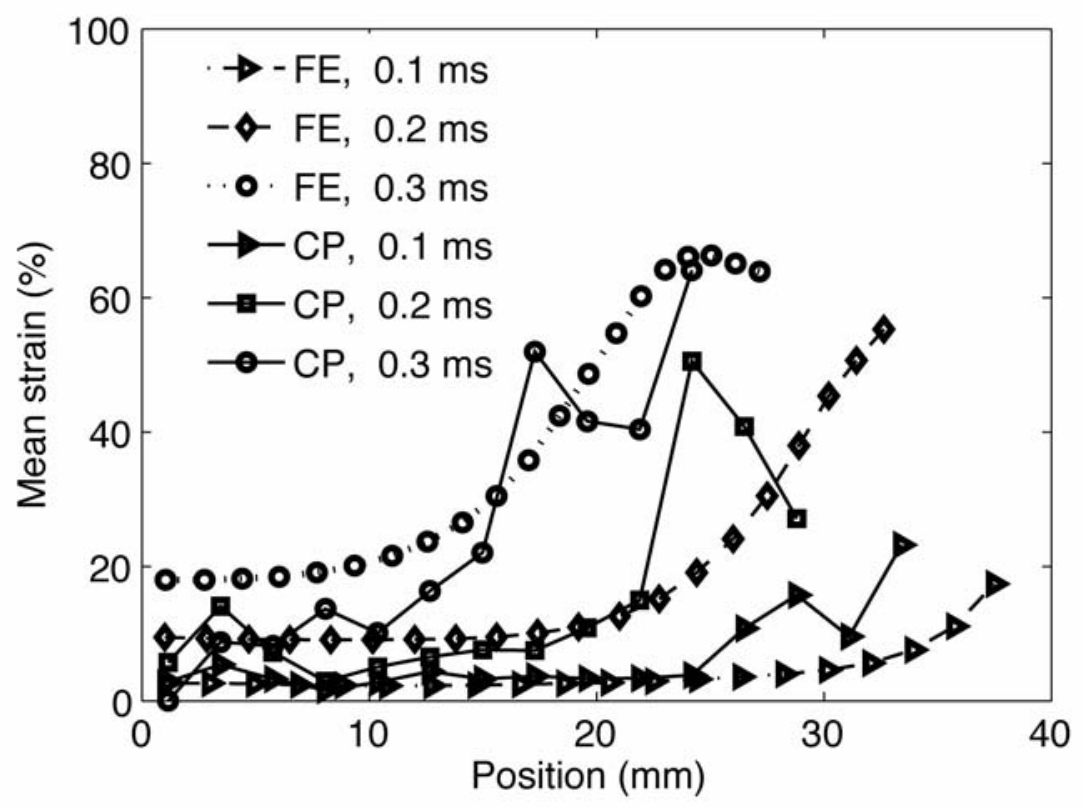

Figure 10. Comparison of simulated (FE) and measured (CP) strain discontinuity profiles

With this simulation method, a prediction of stress jump for different materials at any given impact velocity is obtained. Table 1 gives a prediction of the stress enhancement ratio across shock font for Alporas foam up to $200 \mathrm{~m} / \mathrm{s}$. Such prediction at $55 \mathrm{~m} / \mathrm{s}$ corresponds to that experimentally measured at $55 \mathrm{~m} / \mathrm{s}$. This ratio for Cymat foam shows a huge shock enhancement ratio for high impact speed (see also Tan et al. 2005), even though no shock front is clearly measured at $45 \mathrm{~m} / \mathrm{s}$ by our device.

Table 1. Simulated shock enhancement for Alporas and Cymat foams

\begin{tabular}{|c|c|c|c|}
\hline Speed & $\begin{array}{c}\left(\sigma_{\text {shock }}-\sigma_{y}\right) / \sigma_{y} \\
\text { Alporas }\end{array}$ & Speed & $\begin{array}{c}\left(\sigma_{\text {shock }}-\sigma_{y}\right) / \sigma_{y} \\
\text { Cymat }\end{array}$ \\
\hline $56 \mathrm{~m} / \mathrm{s}$ & 0.44 & $44 \mathrm{~m} / \mathrm{s}$ & 0.20 \\
\hline $100 \mathrm{~m} / \mathrm{s}$ & 1.4 & $100 \mathrm{~m} / \mathrm{s}$ & 0.63 \\
\hline $150 \mathrm{~m} / \mathrm{s}$ & 3.2 & $150 \mathrm{~m} / \mathrm{s}$ & 1.45 \\
\hline $200 \mathrm{~m} / \mathrm{s}$ & 5.4 & $200 \mathrm{~m} / \mathrm{s}$ & 2.68 \\
\hline
\end{tabular}




\section{Numerical shock enhancement and RPRL shock model}

In the previous simulations, the foam is represented by a rate insensitive and macroscopic constitutive law. Simulations for other tested materials such as hollow spheres, Cymat foams and honeycombs are also performed with the same numerical procedure. The only difference is the global phenomenological law used (Figure 11).

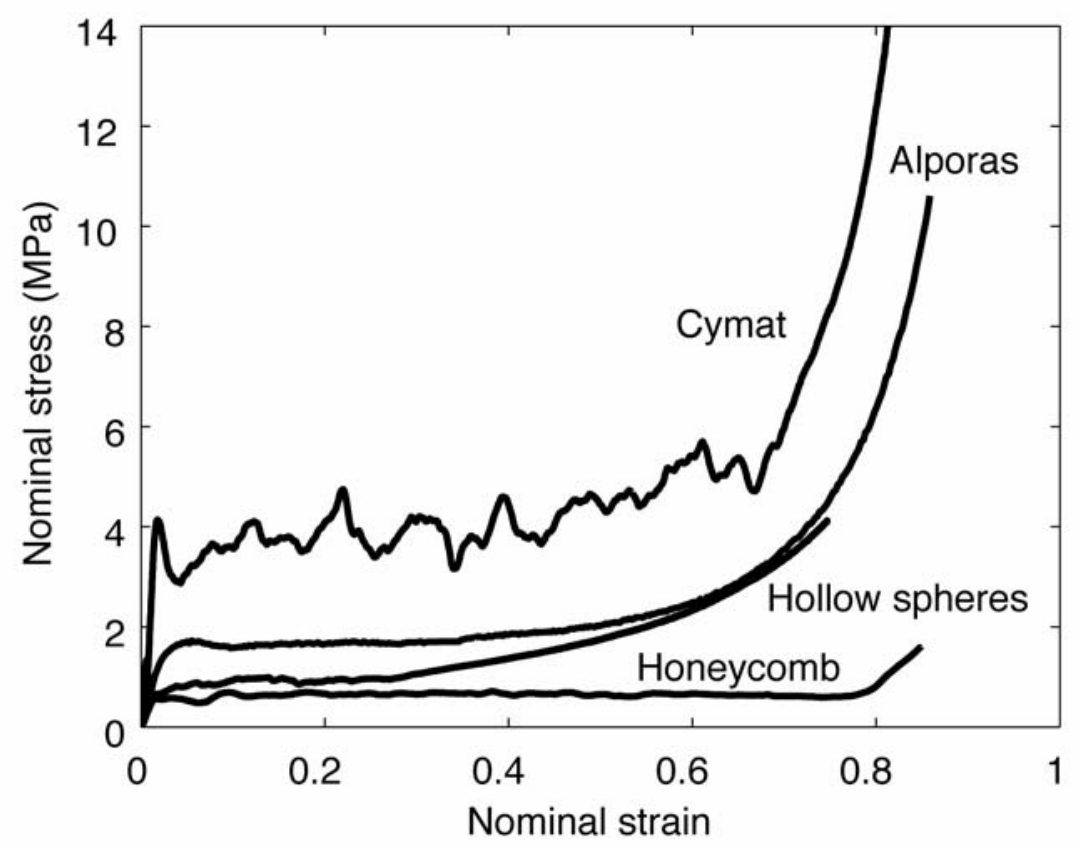

Figure 11. Typical quasi-static behaviour of tested materials

It means that the microscopic nature has no significance for shock enhancement, provided the macroscopic nominal stress-strain curve is identical. It also means that shock enhancement is a structural effect that is numerically reproducible for any concave stress-strain relationship. Therefore, it should not be considered as an intrinsic part of the material behaviour and should not be integrated into the constitutive law.

To eliminate such shock enhancement, a simple rule is to ensure that the measuring system is always placed ahead of the shock front during the test. It is unfortunately not always possible because of the used experimental set-up.

Consequently, a simple shock model should be used to provide an acceptable prediction. Let us consider the RPPL model. Following the same definitions as those used before (see companion paper), $\rho_{0}, \sigma_{y}, \varepsilon_{\text {lock }}$ denote the initial density, the plastic flow stress and the locking strain, and $V_{\text {impact }}, \sigma_{\text {shock }}, U$ the initial impact velocity, the stress behind the shock 
front and the shock front velocity, respectively. With the simplifications of the RPPL model, the shock front velocity and stress behind the shock front are calculated as

$$
\mathrm{U}=\frac{\mathrm{V}_{\text {impact }}}{\varepsilon_{\text {lock }}}, \sigma_{\text {shock }}-\sigma_{y}=\frac{\rho_{0} V_{\text {impact }}^{2}}{\varepsilon_{\text {lock }}}
$$

Arbitrary identification is carried out for the average flow stress and the locking strain from the nominal stress-strain curve (Figure 11). Identified values of the basic mechanical parameters for the studied materials are given in Table 2. The flow stress in Table 2 is defined as the average plateau stress under quasi-static loading. The locking strain is defined visually.

Table 2. Basic mechanical data of the studied materials

\begin{tabular}{cccc}
\hline Materials & Density $\left(\mathrm{kg} / \mathrm{m}^{3}\right)$ & Flow stress $(\mathrm{MPa})$ & Locking strain \\
\hline Alporas & 245 & 1.8 & 0.7 \\
Hollow spheres & 219 & 1.1 & 0.7 \\
Cymat foam & 235 & 3.8 & 0.6 \\
Honeycomb & 38 & 0.6 & 0.8 \\
\hline
\end{tabular}

Equation (4) shows that the shock enhancement ratio $\left(\sigma_{\text {shock }}-\sigma_{y}\right) / \sigma_{y}$ is determined by the ratio between the density and the flow stress multiplied by the locking strain $\rho_{0} / \varepsilon_{\text {lock }} \sigma_{y}$. An increase of this value yields an increase of the shock enhancement ratio. A comparison between the RPPL model prediction and the experimentally measured shock enhancement is given in Table 3.

Table 3. Comparison between experimental data and RPRL predictions

\begin{tabular}{|c|c|c|c|c|c|}
\hline Materials & $\frac{\rho_{0}}{\varepsilon_{\text {lock }} \sigma_{\mathrm{y}}}$ & $\begin{array}{c}\left(\sigma_{\text {shock }}-\sigma_{y}\right) / \sigma_{y} \\
\text { experiment }\end{array}$ & $\begin{array}{c}\left(\sigma_{\text {shock }}-\sigma_{y}\right) / \sigma_{y} \\
\text { model }\end{array}$ & $\begin{array}{c}U(\mathrm{~m} / \mathrm{s}) \\
\text { experiment }\end{array}$ & $\begin{array}{c}U(\mathrm{~m} / \mathrm{s}) \\
\text { model }\end{array}$ \\
\hline Alporas $(55 \mathrm{~m} / \mathrm{s})$ & $1.80 \times 10^{-4}$ & 0.44 & 0.54 & $94(87)$ & 78 \\
\hline Hollow sphere $(55 \mathrm{~m} / \mathrm{s})$ & $2.84 \times 10^{-4}$ & 0.66 & 0.86 & 107 & 78 \\
\hline Cymat foam $(45 \mathrm{~m} / \mathrm{s})$ & $1.03 \times 10^{-4}$ & 0. & 0.21 & - & - \\
\hline Honeycomb $(45 \mathrm{~m} / \mathrm{s})$ & $0.79 \times 10^{-4}$ & 0. & 0.15 & - & - \\
\hline
\end{tabular}


Such model may explain why Alporas foams as well as hollow spheres have a more significant enhancement, whereas Cymat foams and honeycombs exhibit almost no effect. One important remark is that Cymat foams as well as honeycombs would also exhibit a shock effect for high impact velocities, which was observed for Cymat foams (Tan et al., 2002). The present simulations on honeycombs show also shock enhancement at higher impact speeds.

\section{Power law shock model}

\subsection{Parameter sensitivity of RPPL model}

From the aforementioned predictions (Table 3), it is shown that the RPPL model does provide a first-order approximation. However, the identification of the parameters of the model is not easy. The plastic flow stress $\sigma_{y}$ is more or less easy to identify, the value of the locking strain is arbitrary due to the non-linear shape of the densification curve. The shock front velocity and the stress behind the shock front are very sensitive to this locking strain. Figure 12 shows the change of these values predicted by the RPPL model with the locking strain for five different initial impact velocities $(20,40,80,200$ and $300 \mathrm{~m} / \mathrm{s})$. The difference is really significant for different values of the locking strain, especially for high impact velocities.

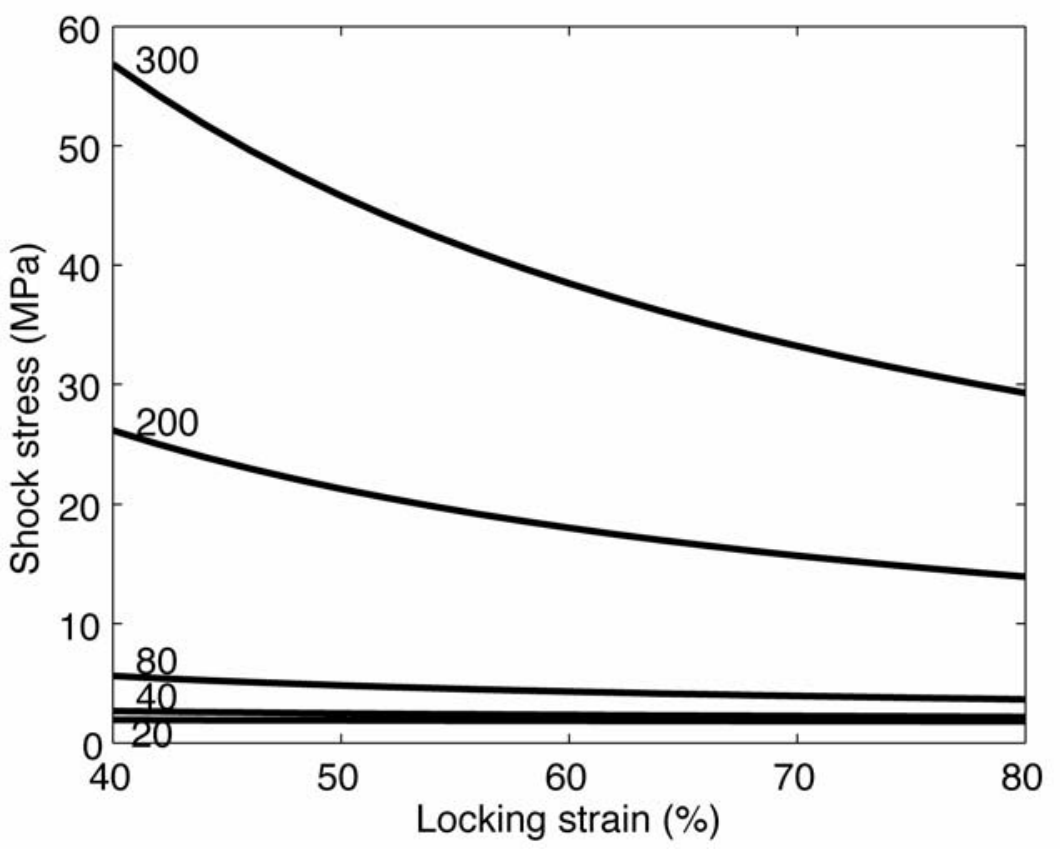

a) 
b)

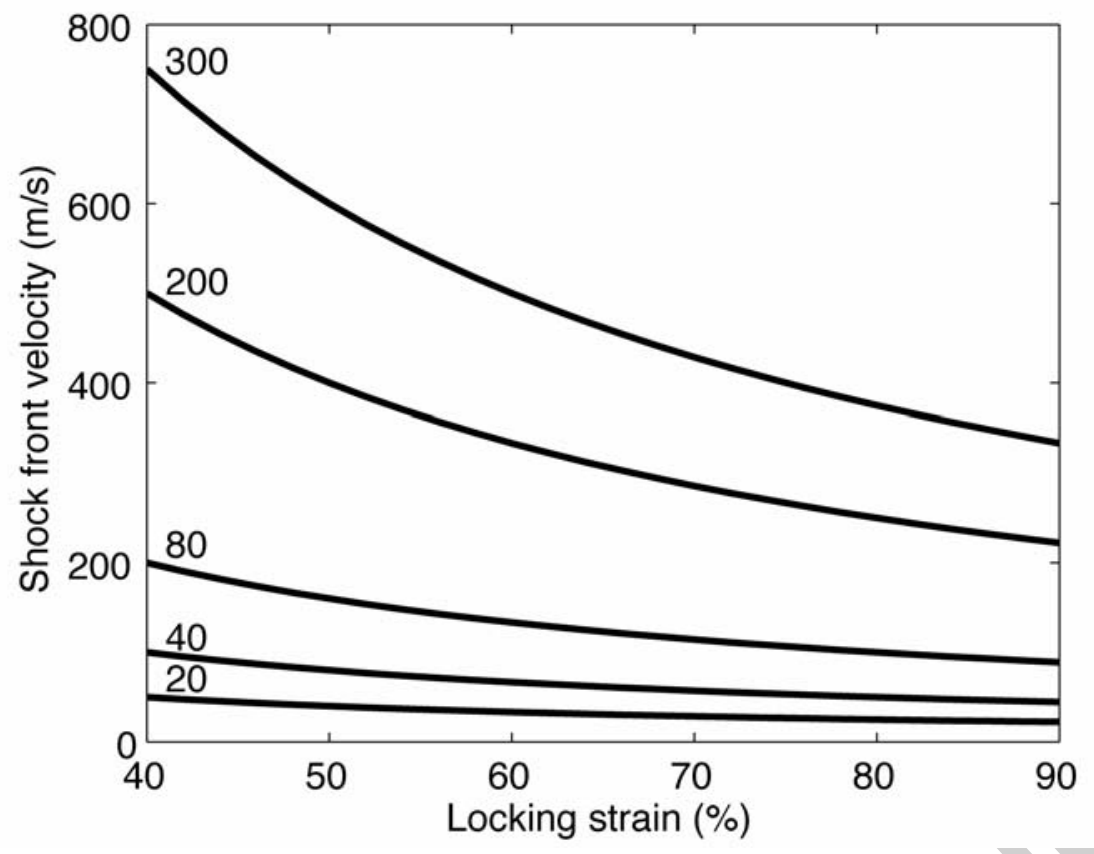

Figure 12. Dependence of the shock front velocity (a) and shock stress (b) with the locking strain for the RPRL model when five impact velocities (in $\mathrm{m} / \mathrm{s}$ ) are considered

To overcome this identification difficulty, we propose to account for the progressive densification feature. The same impact case as discussed in Eqn. (4) is considered. The fact that the densification is progressive implies that the strain reached behind the shock front $\varepsilon_{\text {shock }}$ is not explicitly known as the locking strain in the RPPL model. The basic continuity equations (4) are replaced by

$$
U=\frac{V_{\text {impact }}}{\varepsilon_{\text {shock }}} \text { and } \sigma_{\text {shock }}-\sigma_{y}=\frac{\rho_{0} V_{\text {impact }}^{2}}{\varepsilon_{\text {shock }}}
$$

and the solution is defined by using the stress-strain relation of the material

$$
\sigma_{\text {shock }}=f\left(\varepsilon_{\text {shock }}\right)
$$

Considering the case of Alporas foams, where the stress-strain curve is given in Figure 13, a numerical solution is obtained from equations $(5 \mathrm{a}, 5 \mathrm{~b})$. Using a polynomial approximation of relation (5b) obtained from experimental stress-strain relationships (Figure 11) with a curvefitting technique, on evaluates numerically the strain behind the shock front $\varepsilon_{\text {shock }}$ with respect 
to the impact velocity. The numerical result of the change of this value with respect to the impact velocity is plotted in Figure 13 where the solid line is the curve fit of experimental data (points). The circles in this figure show the shock strain and stress behind the shock front for different impact velocities. One notes that the value of the shock strain $\varepsilon_{\text {shock }}$ varies in a wide range, namely, from $60 \%$ for an impact velocity of $50 \mathrm{~m} / \mathrm{s}$, to $90 \%$ at $300 \mathrm{~m} / \mathrm{s}$.

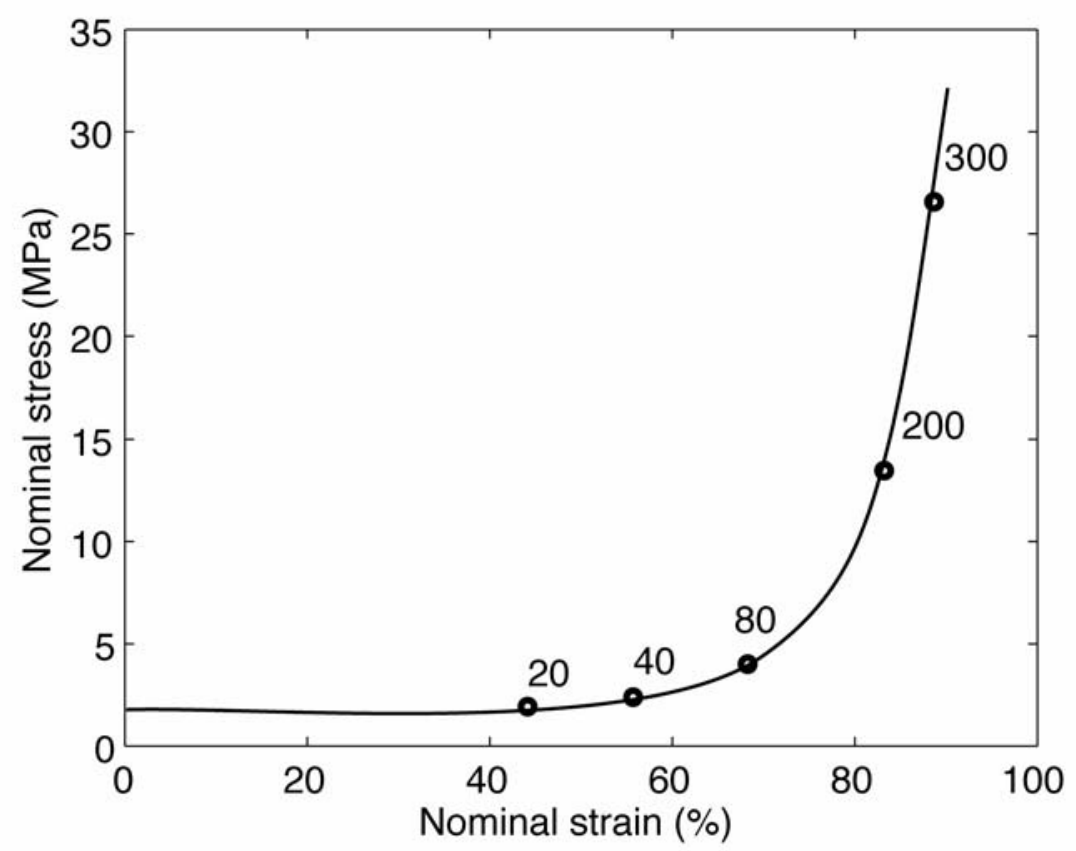

Figure 13. Change of shock strain for five values of the impact velocity (in $\mathrm{m} / \mathrm{s}$ )

\subsection{An improved shock model with a hardening locking}

The aforementioned analysis shows the need for improving the RPPL model. A numerical solution may be obtained by solving equations (5). However, for a simple use, an explicit closed-form solution is preferred. We propose to introduce a model using a power law without locking strain to replace the RPPL model. The densification curve is defined by the initial yield stress $\sigma_{y}$, the power $m$, and the coefficient $k$

$$
\sigma=\sigma_{\mathrm{y}}+\mathrm{k} \varepsilon^{\mathrm{m}}
$$

Equations (5a) and (6) then lead to

$$
\mathrm{k} \varepsilon_{\text {shock }}^{\mathrm{m}}=\frac{\rho_{0} \mathrm{~V}_{\text {impact }}^{2}}{\varepsilon_{\text {shock }}}
$$

The derivation of the shock strain $\varepsilon_{\text {shock }}$ is straight forward 


$$
\varepsilon_{\text {shock }}=\left(\frac{\rho_{0} V_{\text {impact }}^{2}}{k}\right)^{\frac{1}{m+1}}
$$

and the shock front velocity reads

$$
U=\left(\frac{k V_{\text {impact }}^{m-1}}{\rho_{0}}\right)^{\frac{1}{m+1}}
$$

From experimental stress-strain data, it is easy to identify such model. Table 4 provides the parameters for the four studied materials.

Table 4. Identified parameters for power law locking

\begin{tabular}{|c|c|c|c|}
\hline Material & $\sigma_{y}(\mathrm{MPa})$ & $m$ & $K(\mathrm{MPa})$ \\
\hline Alporas & 1.70 & 6.40 & 21.2 \\
\hline Hollow sphere & 0.97 & 3.536 & 8.48 \\
\hline Cymat foam & 3.97 & 8.99 & 48.3 \\
\hline Honeycomb & 0.671 & 38.19 & 653 \\
\hline
\end{tabular}

The quality of tuning for Alporas foam is shown in Figure 14 as an example.

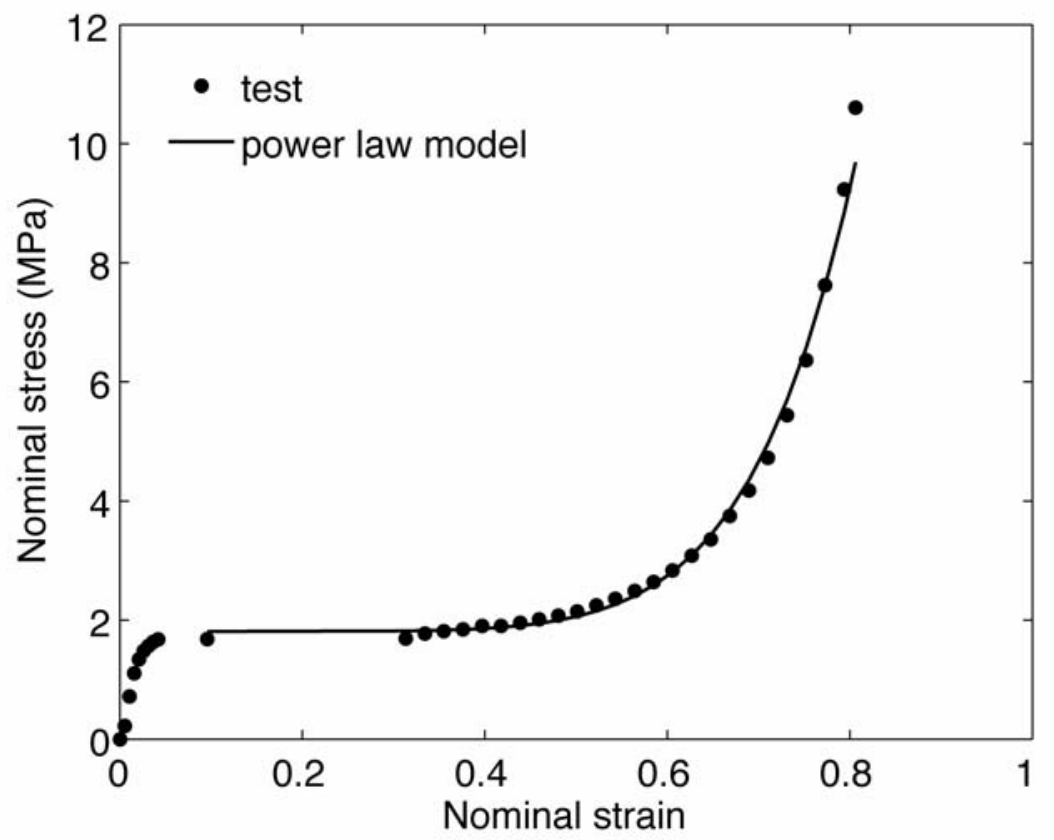

Figure 14. Power law model identification for Alporas foam 
Figure 15 gives the change of the shock front velocity with the impact velocity for different models of the stress-strain curve. The dashed lines are the results that would be given by the RPPL for two limiting values of the locking strain, namely, $60 \%$ and $80 \%$. It shows that the explicit solution of a power law model gives a satisfactory prediction.

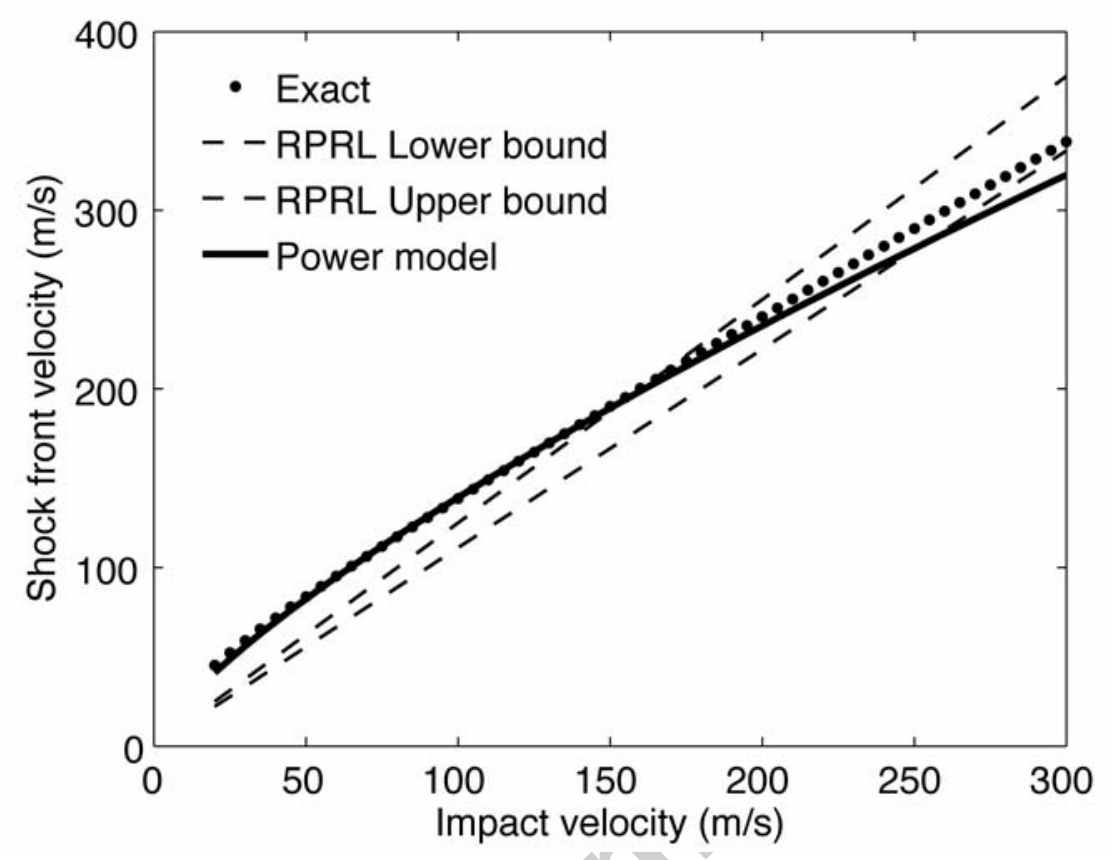

Figure 15. Comparison of models in terms of shock front velocity vs. impact velocity

From this power law model with identified parameters (Table 4), the relative shock stress jump $\left(\sigma_{\text {shock }}-\sigma_{y}\right) / \sigma_{y}$ is also obtained. The shock enhancement effect for those four materials is plotted in Figure 16. 


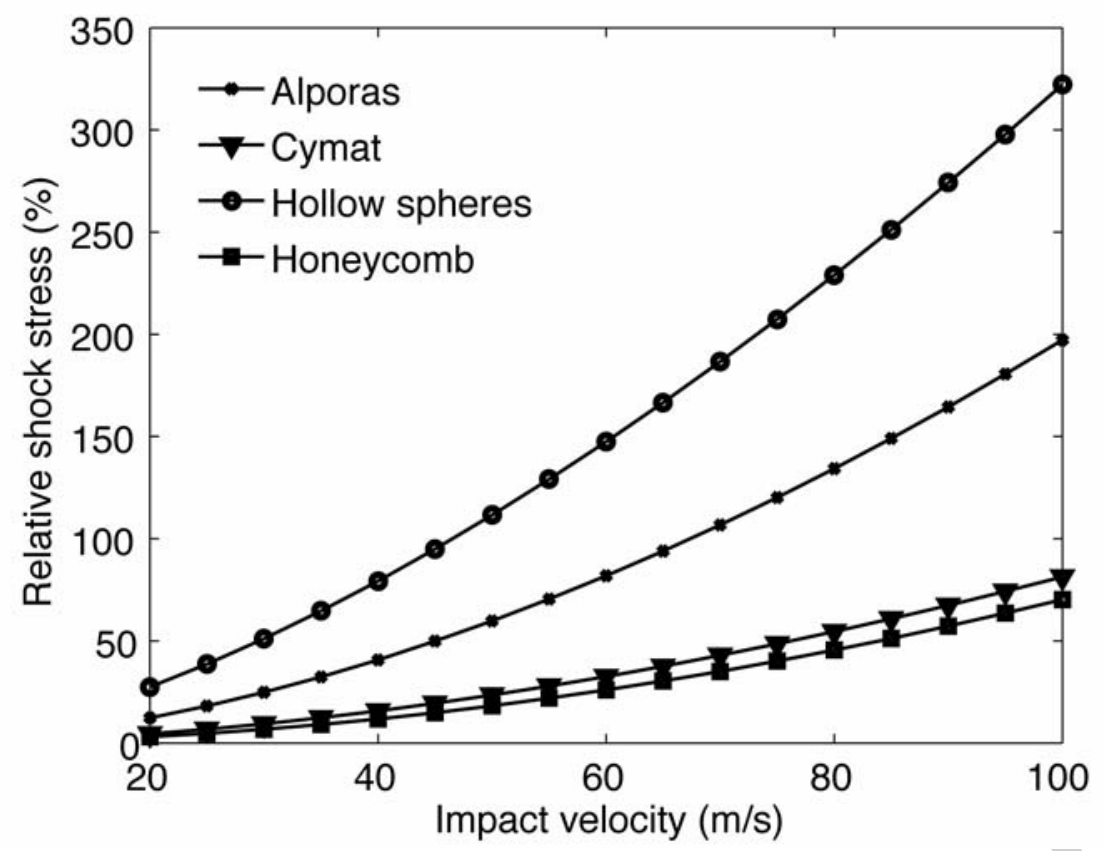

Figure 16 Shock enhancement effect for the four studied materials

The comparison between FEM simulation results for Alporas and Cymat foams (Table 2) and present model is given in Figure 17. A reasonable agreement is found.

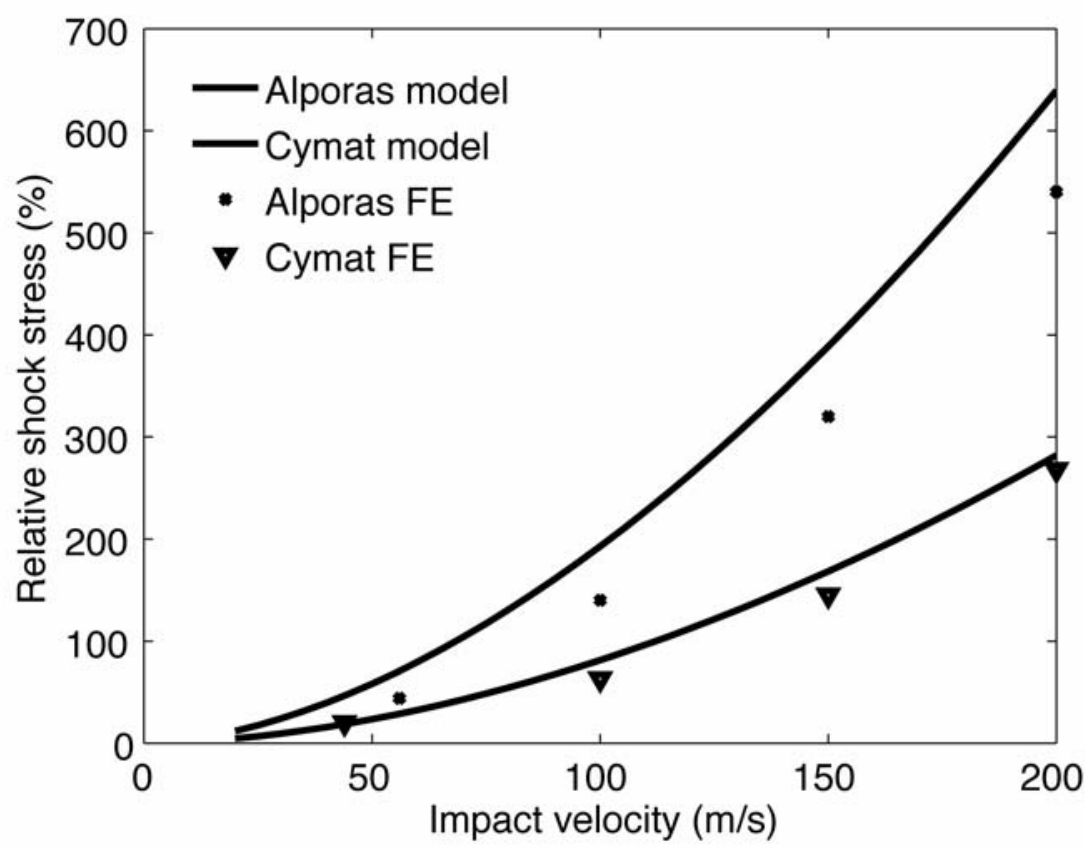

Figure 17 Comparison between FEM analyses and power model for the prediction of the relative shock stress vs. impact velocity. 


\section{Conclusion}

In this paper, numerical simulations of tests in two different configurations are performed with an industrial explicit FE code. The results show that shock enhancement of foams is reproduced by numerical simulations using a simple macroscopic, homogenous and rate-insensitive constitutive law based on a nominal stress-strain relationship obtained in a quasi-static compression test. It means that such shock enhancement effect should not be taken into account at the level of the constitutive law itself. Shock enhancement of cellular materials is governed by macroscopic structural parameters. Test results on cellular materials with different base materials and microstructures show that such enhancement is independent of the microstructure and the local crushing deforming mode.

Last, the widely-used RPPL model is shown to be very sensitive to the identification uncertainty of the constitutive parameters. Since the rigid locking strain is only determined in an arbitrary manner, the RPPL model is not accurate enough, especially for low impact velocities (i.e., less than $100 \mathrm{~m} / \mathrm{s}$ ). Since experimental and numerical results show that the strain behind the shock front depends on the impact velocity, the RPPL model considering this value as a constant (locking strain) cannot be accurate. An improved model based on a power law densification assumption allows for an easy determination of its parameters from experimental data, and gives results in good agreement with experimental data. 


\section{References}

Elnasri, I., Pattofatto S., Zhao, H., Tsitsiris, H., Hild F., Girard, Y., 2007, Shock enhancement of cellular structures under impact loading: Part I Experiments, J. Mech. Phys. Solids, submitted.

Hallquist J.O. Ls-Dyna theoretical manual. Livermore Software Technology Corporation, 1998.

Radford, D.D., Deshpande, V.S., Fleck, N.A., 2005, The use of metal foam projectile to simulate shock loading on a structure, Int. J. Impact Engng., 31, 1152-1171.

Reid, S.R., Peng, C., 1997, Dynamic uniaxial crushing of wood, Int. J. Impact Engng., 19, 531-570.

Lopatnikov, S.L., Gama, B.A., Haque, Md. J., Krauthauser, C., Gillespie, J.W., Guden, M., Hall, I.W., 2003, Dynamics of metal foam deformation during Taylor cylinderHopkinson impact experiment, Composite structure, 61, 61-71.

Lopatnikov, S.L., Gama, B.A., Haque, Md. J., Krauthauser, C., Gillespie, J.W., Guden, M., 2004, High-velocity plate impact of metal foams, Int. J. Impact Engng., 30, 421-445.

Tan, P.J., Harrigan, J.J., Reid, S.R., 2002, Inertia effects in uniaxial dynamic compression of a closed cell aluminium alloy foam, Material Science \& Technology, 18, 480-488.

Tan, P.J., Reid, S.R., Harrigan, J.J., Zou, Z., Li, S., 2005, Dynamic compressive strength properties of aluminium foams. Part I-experimental data and observations, J. Mech. Phys. Solids, 53, 2174-2205

Zhao, H., Nasri, I., Abdennadher, S., 2005, An experimental study on the behaviour under impact loading of metallic cellular materials, Int. J. Mech. Sci., 47, 757-774. 